\title{
KEMAMPUAN PEMECAHAN MASALAH SISWA SMAN 6 KITA BENGKULU DENGAN PENERAPAN MODEL PEMBELAJARAN PENEMUAN BERBANTUAN MEDIA ANIMASI
}

\author{
Andik Puwanto $^{1,}$ a) , Sri Wahyuni, ${ }^{1, \text { b) }}$ \\ ${ }^{1}$ Program Studi Pendidikan Fisika FKIPUniversitas Bengkulu. \\ Email: ${ }^{\text {a) }}$ andik.purwanto@unib.ac.id
}

\begin{abstract}
Abstrak
Penelitian ini bertujuan untuk menguji pengaruh model pembelajaran penemuan dengan berbantuan media animasi terhadap kemampuan pemecahan masalah siswa di SMAN 6 Kota Bengkulu. Jenis penelitian ini adalah Quasi Experiment. Sampel penelitian yang diambil menggunakan teknik sampling purposive yang sebelumnya telah diuji normalitas dan homogenitas diperoleh kelas X MIPA C sebagai kelas eksperimen dan X MIPA D sebagai kelas kontrol. Teknik pengumpulan data menggunakan tes kemampuan pemecahan masalah siswa. Analisis data menggunakan analisis deskriptif dan inferensial. Persyaratan uji normalitas dengan uji chi-kuadrat dan uji homogenitas dengan perbandingan varians terbesar dengan varians terkecil serta uji $t$ separated varians. Hasil penelitian memperlihatkan skor kemampuan pemecahan masalah siswa kelas eksperimen dan kelas kontrol berbeda, yaitu $t_{\text {hitung }}$ lebih besar dari $t_{\text {tabel }}(7,55>1,99)$ taraf signifikan $(\alpha=0,05)$. Berdasarkan hasil penelitian dapat disimpulkan bahwa terdapat pengaruh penerapan model pembelajaran penemuan dengan berbantuan media animasi terhadap kemampuan pemecahan masalah siswa SMAN 6 Kota Bengkulu.
\end{abstract}

Kata-kata kunci: Model Pembelajaran Penemuan, Media Animasi, dan Kemampuan Pemecahan Masalah.

\begin{abstract}
This study aims to examine the effect of learning model of discovery with the aid of animation media on student problem-solving skills in SMAN 6 Kota Bengkulu. This type of research is Quasi-Experiment. The samples taken using purposive sampling technique that has been tested for normality and homogeneity are obtained by class X MIPA C as experiment class and X MIPA D as control class. Data collection techniques use student problem-solving skills tests. Data analysis using descriptive and inferential analysis. Normality test requirements with chi-square test and homogeneity test with the most significant variance ratio with the smallest variance and t-test separated variance. The result of the research shows the score of the problem-solving ability of the students of the experimental class and the control class is different, that is tcount is bigger than ttable (7.55>1.99) significant level $(\alpha=0,05)$. Based on the results of this study it can be concluded that there is an effect of applying learning model of discovery with the aid of animation media to solving problems of students of SMAN 6 Kota Bengkulu.
\end{abstract}

Keywords: Discovery Learning Model, Media Animation, and Problem Solving Skills. 


\section{PENDAHULUAN}

Pendidikan pada dasarnya adalah usaha sadar untuk menumbuh kembangkan potensi peserta didik dengan cara mendorong dan memfasilitasi kegiatan belajar. Sebagaimana yang tercantum dalam Undang-Undang Nomor 20 Tahun 2003 tentang Sistem Pendidikan Nasional pada Pasal 1 Butir 1, bahwa "Pendidikan nasional adalah usaha sadar dan terencana untuk mewujudkan suasana belajar dan proses pembelajaran agar peserta didik secara aktif mengembangkan potensi dirinya untuk memiliki kekuatan spiritual keagamaan, pengendalian diri, kepribadian, kecerdasan, akhlak mulia, dan keterampilan yang diperlukan dirinya, masyarakat, bangsa, dan negara" [2].

Untuk mencapai kualitas seperti yang diharapkan dalam tujuan pendidikan nasional, peningkatan pendidikan harus selalu diusahakan baik dari segi kualitas maupun segi kuantitas. Sesuai dengan Permendikbud No.65 tahun 2013 tentang standar proses pendidikan dasar dan menengah menetapkan bahwa perencanaan pembelajaran diracang dalam bentuk silabus dan rencana pelaksanaan pembelajaran (RPP), penilaian proses pembelajaran menggunakan pendekatan penilaian otentik (authentic assesment) yang menilai kesiapan siswa, proses, dan hasil belajar secara utuh.

Pembelajaran fisika merupakan salah satu sarana untuk melatih siswa secara cermat dan tepat dalam memecahkan masalah dan memahami konsep-konsep fisika. Namun, fisika bukanlah mata pelajaran (mapel) yang banyak disenangi dan diminati oleh siswa. Hal ini juga terhadi di SMAN 6 Kota Bengkulu didapatkan bahwa fisika dianggap sebagai mapel yang sulit untuk dipahami, karena banyak menggunakan rumus-rumus rumit dan dipenuhi dengan teori-teori yang kurang menarik serta susah untuk diingat.

Upaya untuk meningkatkan kecintaan terhadap fisika adalah memanfaatkan media pembelajaran. Jika guru memanfaatkan media belajar secara lebih maksimal maka secara langsung siswa mendapatkan pengalaman belajar yang lebih aktif, kreatif dan bermakna. Sudjana dan Rivai mengemukakan bahwa kemampuan penalaran siswa yang tinggi dapat dilatih dengan meningkatkan daya visualisasi siswa [5]. Melalui berbagai tampilan teks, suara, gambar, video, animasi, simulasi, dapat meningkatkan kemampuan penalaran. Kosasih menyatakan bahwa media pengajaran dapat memperbaiki proses belajar siswa dalam pengajaran yang pada gilirannya diharapkan dapat meningkatkan hasil belajar yang dicapainya [1]. Berdasarkan pemaparan di atas, maka diperlukan suatu kajian yang diharapkan dapat memperbaiki kegiatan pembelajaran yang lebih sistematis. Pada kurikulum 2013, terdapat tiga jenis model pembelajaran yang disarankan untuk tercapainya hasil belajar, yakni model pembelajaran penemuan, model pembelajaran berbasis masalah dan model pembelajaran berbasis proyek [1]. Oleh karena itu, berdasarkan masalah diatas maka salah satu strategi pembelajaran untuk mengatasinya berdasarkan kurikulum 2013 yang digunakan yaitu dengan menggunakan model pembelajaran penemuan (discovery learning model). Pada model pembelajaran penemuan siswa didorong untuk belajar secara aktif dengan menemukan sendiri, menyelidiki sendiri dengan bantuan media animasi yang dalam pembelajaran ini menggunakan alat indera seperti, penglihatan dan pendengaran maka hasil yang diperoleh akan tahan lama dan tidak mudah dilupakan oleh siswa [2].

Pengaplikasian model pembelajaran penemuan dalam pembelajaran, terdapat beberapa tahapan yang harus dilaksanakan. Syah [10] mengemukakan langkah-langkah operasional model pembelajaran penemuan yaitu sebagai berikut:

TABEL 1. Langkah-langkah operasional model pembelajaran penemuan

\begin{tabular}{cll}
\hline No & \multicolumn{1}{c}{ Langkah Model Penemuan } & \multicolumn{2}{c}{ Kegiatan Pembelajaran } \\
\hline 1 & $\begin{array}{l}\text { Stimulation } \text { (stimulasi/pemberian } \\
\text { rangsangan) }\end{array}$ & Pada tahap ini siswa dihadapkan pada \\
& & sesuatu yang menimbulkan kebingungan, \\
& kemudian dilanjutkan untuk tidak memberi \\
& generalisasi, agar timbul keinginan untuk \\
& menyelidiki sendiri. Guru dapat memulai \\
& dengan mengajukan pertanyaan, anjuran \\
& membaca buku, dan belajar lainnya yang \\
& mengarah pada persiapan pemecahan \\
& masalah. & \\
\hline
\end{tabular}




\begin{tabular}{|c|c|c|}
\hline 2 & $\begin{array}{l}\text { Problem statemen } \\
\text { (pernyataan/identifikasi masalah) }\end{array}$ & $\begin{array}{l}\text { Guru memberikan kesempatan kepada } \\
\text { siswa untuk mengidentifikasi masalah- } \\
\text { masalah yang relevan dengan bahan } \\
\text { pelajaran, kemudian salah satunya dipilih dan } \\
\text { dirumuskan dalam bentuk hipotesis }\end{array}$ \\
\hline 3 & $\begin{array}{l}\text { Data collection (pengumpulan } \\
\text { data) }\end{array}$ & $\begin{array}{l}\text { Tahap ini siswa diberi kesempatan untuk } \\
\text { mengumpulkan berbagai informasi yang } \\
\text { relevan, membaca literatur, mengamati objek, } \\
\text { wawancara, melakukan uji coba sendiri untuk } \\
\text { menjawab pertanyaan atau membuktikan } \\
\text { benar tidaknya hipotesis. }\end{array}$ \\
\hline 4 & Data processing (pengolahan data) & $\begin{array}{l}\text { Pengolahan data merupakan kegiatan } \\
\text { mengolah data dan informasi yang telah } \\
\text { diperoleh siswa melalui wawancara, observasi } \\
\text { dan sebagainya, lalu ditafsirkan. }\end{array}$ \\
\hline 5 & Verification (pembuktian) & $\begin{array}{l}\text { Pada tahap ini siswa melalakukan } \\
\text { pemeriksaan secara cermat untuk } \\
\text { membuktikan benar atau tidaknya hipotesis } \\
\text { yang ditetapkan tadi dengan temuan alternatif } \\
\text { dan dihubungkan dengan hasil pengolahan } \\
\text { data. }\end{array}$ \\
\hline 6 & $\begin{array}{l}\text { Generalization (menarik } \\
\text { kesimpulan) }\end{array}$ & $\begin{array}{l}\text { Tahap generalisasi/menarik kesimpulan } \\
\text { adalah proses menarik sebuah kesimpulan } \\
\text { yang dapat dijadikan prinsip umum dan } \\
\text { berlaku untuk semua kejadian atau masalah } \\
\text { yang sama, dengan memperhatikan hasil } \\
\text { verifikasi. }\end{array}$ \\
\hline
\end{tabular}

\section{METODE PENELITIAN}

Penelitian yang dilaksanakan dalam penelitian ini yaitu metode kuasi eksperimen atau eksperimen semu yaitu metode yang mempunyai kelompok kontrol, tetapi tidak dapat berfungsi sepenuhnya untuk mengontrol variabel-variabel luar yang mempengaruhi eksperimen [4]. Penelitian ini dilakukan menggunakan desain nonequivalent control group [4].

TABEL 2. Desain Nonequivalent Control Group

\begin{tabular}{lccc}
\hline Kelas Eksperimen & $\mathrm{O}_{1}$ & $\mathrm{X}$ & $\mathrm{O}_{2}$ \\
Kelas Kontrol & $\mathrm{O}_{3}$ & - & $\mathrm{O}_{4}$ \\
\hline
\end{tabular}

Data yang diperoleh dalam penelitian ini adalah data hasil belajar, kemampuan pemecahan masalah dan minat belajar. Analisis inferensial yang digunakan adalah uji normalitas yaitu chi kuadrat dan uji homogenitas adalah sama varians. Jika data yang didapatkan berdistribusi normal dan homogen, uji yang digunakan adalah uji t. Rumus t-test yang digunakan adalah sebagai berikut: [4].

$$
t=\frac{\bar{X}_{1}-\bar{X}_{2}}{\sqrt{\frac{s_{1}^{2}}{n_{1}}+\frac{s_{2}^{2}}{n_{2}}}}
$$

Kriteria pengambilan keputusan pada uji hipotesis dengan uji-t adalah jika t hitung lebih kecil dari $\mathrm{t}$ tabel $\left(t_{\text {hitung }}<t_{\text {tabel }}\right)$, maka Ha diterima atau H0 ditolak dengan signifikansi derajat kepercayaan $(\alpha)$ yang digunakan yaitu $5 \%$ atau 0,05 . $\mathrm{T}_{\text {tabel }}$ didapat dari tabel distribusi $\mathrm{t}$ dengan $\mathrm{dk}=\mathrm{n}_{1}+\mathrm{n}_{2}-2$, maka 
terdapat perbedaan yang signifikan sehingga terdapat pengaruh model pembelajaran penemuan dengan berbantuan media animasi terhadap hasil belajar, kemampuan pemecahan masalah dan minat belajar siswa.

\section{HASIL DAN PEMBAHASAN}

\section{Hasil Penelitian}

\section{a. Deskripsi Data Hasil Belajar Aspek Pengetahuan Kelas Eksperimen}

Hasil belajar pada kelas eksperimen yang mengikuti pembelajaran dengan menggunakan model pembelajaran penemuan dengan berbantuan media animasi. Hasil belajar yang dinilai dan dibandingkan untuk kelas eksperimen dan kelas kontrol yaitu pada aspek pengetahuan. Hasil belajar sebelum diberi perlakuan (pretest) dan sesudah diberi perlakuan (posttest) pada kelas eksperimen yang mengikuti pembelajaran dengan menggunakan model pembelajaran penemuan dengan berbantuan media animasi ini dilakukan sebanyak empat kali pertemuan. Grafik data hasil data ratarata pretest dan posttest hasil belajar kelas eksperimen dapat dilihat pada GAMBAR 1.

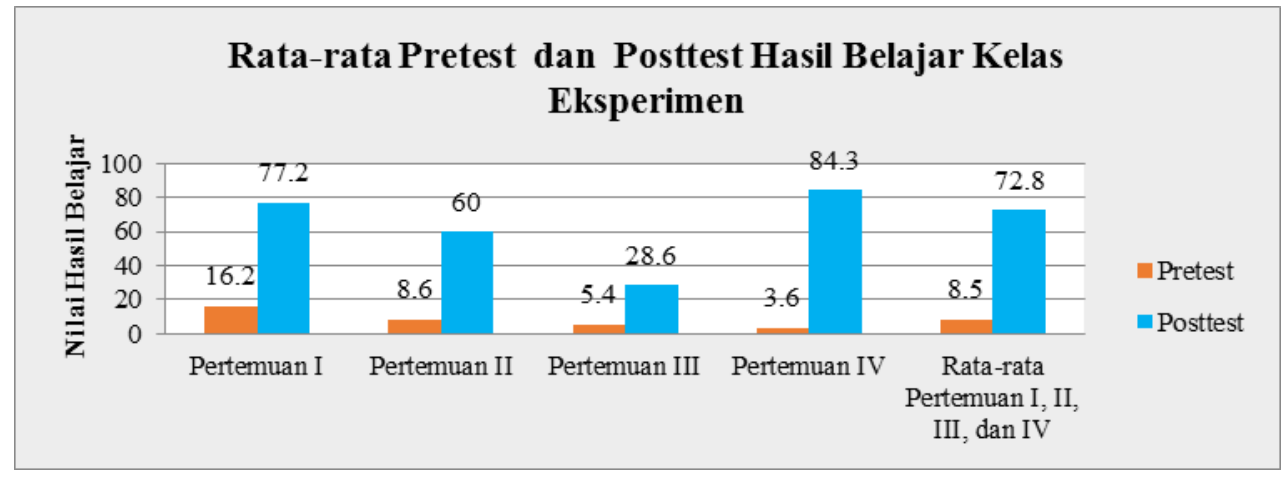

GAMBAR 1. Grafik Data Rata-Rata Pretest dan Posttest Hasil Belajar Kelas Eksperimen

\section{b. Deskripsi Data Kemampuan Pemecahan Masalah Kelas Eksperimen}

Kemampuan pemecahan masalah ini adalah hasil yang digunakan sebagai pembanding dengan kelas kontrol. Kemampuan pemecahan masalah sebelum diberi perlakuan (pretest) dan sesudah diberi perlakuan (posttest) pada kelas eksperimen yang mengikuti pembelajaran dengan menggunakan model pembelajaran penemuan dengan berbantuan animasi ini juga dilakukan sebanyak empat kali pertemuan. Grafik data hasil data rata-rata pretest dan posttest kemampuan pemecahan masalah kelas eksperimen dapat dilihat pada GAMBAR 2.

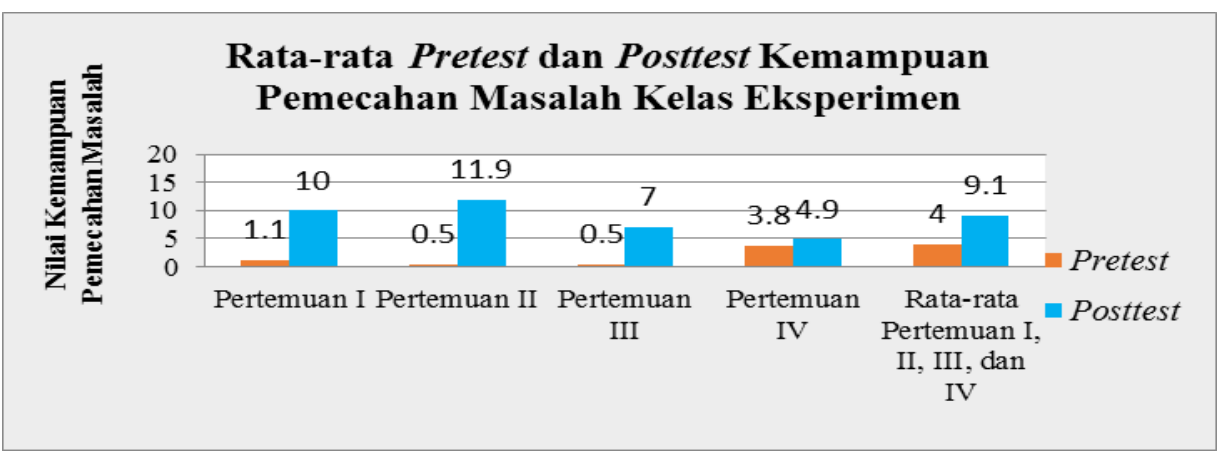

GAMBAR 2. Data rata-rata pretest dan posttest kemampuan pemecahan masalah kelas eksperimen

\section{c. Deskripsi Data Hasil Belajar Aspek Pengetahuan Kelas Kontrol}


Hasil belajar pada kelas kontrol yang mengikuti penggunaan model pembelajaran penemuan. Hasil belajar sebelum diberi perlakuan (pretest) dilakukan sebanyak empat kali pertemuan. Dari keempat hasil pretest tersebut akan diperoleh skor rata-rata (mean). Grafik data hasil data rata-rata pretest dan posttest hasil belajar kelas kontrol dapat dilihat pada GAMBAR 3.

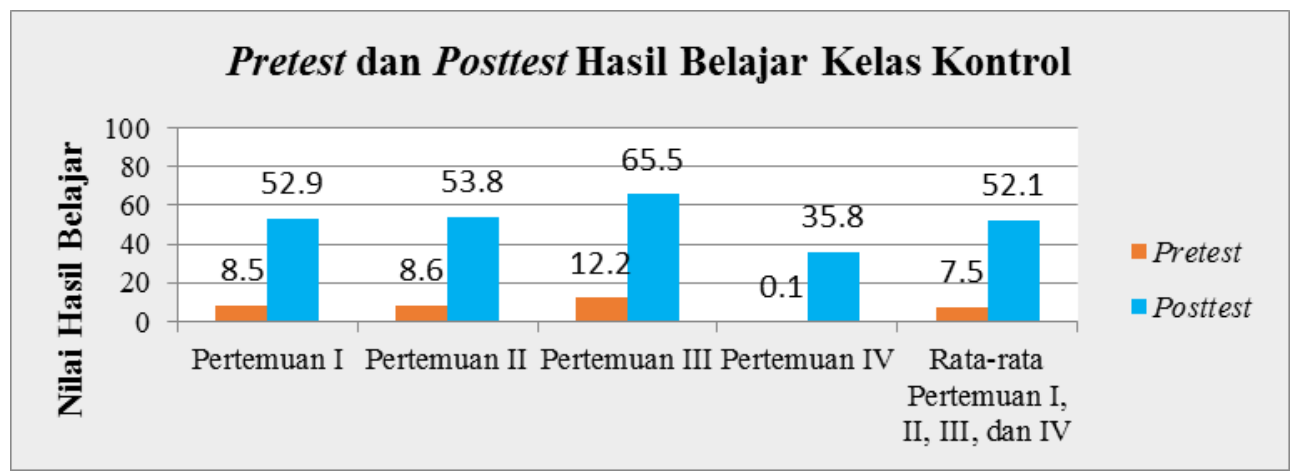

GAMBAR 3. Grafik data rata-rata pretest dan posttest hasil belajar kelas kontrol

\section{d. Deskripsi Data Kemampuan Pemecahan Masalah Kelas Kontrol}

Kemampuan pemecahan masalah ini adalah hasil yang digunakan sebagai pembanding dengan kelas eksperimen. Kemampuan pemecahan masalah sebelum diberi perlakuan (pretest) dan sesudah diberi perlakuan (posttest) pada kelas kontrol yang mengikuti pembelajaran dengan menggunakan model pembelajaran penemuan ini juga dilakukan sebanyak empat kali pertemuan. Keempat hasil pretest dan posttest tersebut akan diperoleh skor rata-rata (mean). Grafik data hasil data rata-rata pretest dan posttest kemampuan pemecahan masalah kelas kontrol dapat dilihat pada GAMBAR 4.

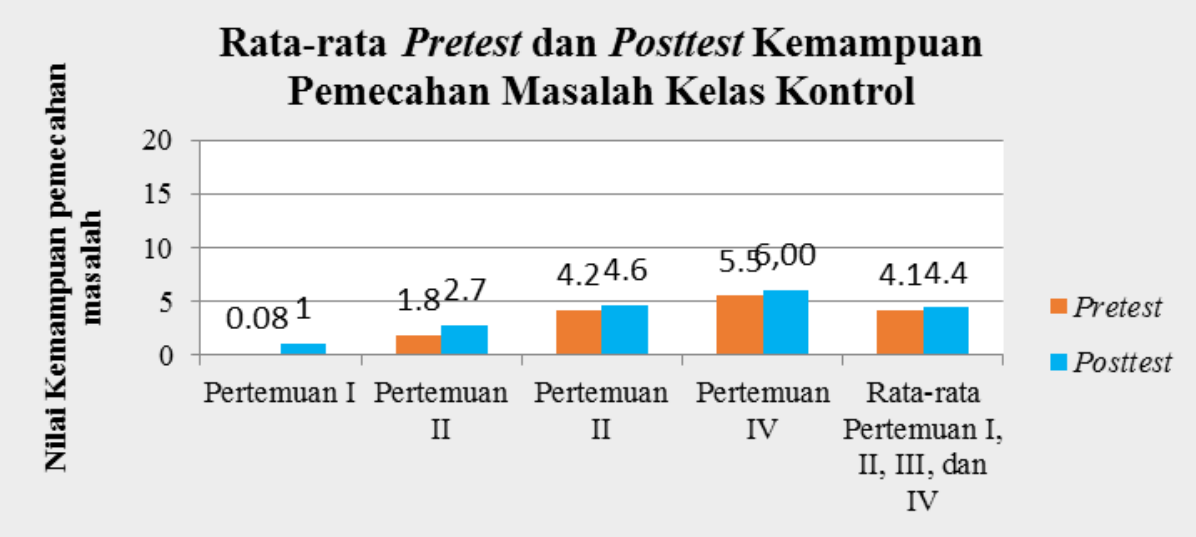

GAMBAR 4. Grafik Data Rata-Rata Pretest dan Posttest Kemampuan Pemecahan Masalah Kelas Kontrol

Uji Inferensial

\section{a. Uji Homogenitas hasil belajar dan kemampuan pemecahan masalah}

Uji homogenitas dilakukan setelah kedua sampel dinyatakan berdistribusi normal. Tujuan dilakukan uji homogenitas ini adalah untuk menentukan apakah sampel berasal dari varians yang homogen, sehingga dibutuhkan varians dari kelas eksperimen dan varians dari kelas kontrol. Sampel dinyatakan homogen apabila $F_{\text {hitung }}<F_{\text {tabel }}$ tapi jika $F_{\text {hitung }}>F_{\text {tabel }}$ maka sampel tidak homogen. Hasil perhitungan uji homogenitas varians ini menggunakan rumus perbandingan vaians terbesar dibagi varians terkecil antara dua kelompok sampel. Adapun hasil uji homogenitas hasil belajar dapat dilihat pada TABEL 3 dan hasil uji homogenitas kemampuan pemecahan masalah pada TABEL 4. 
TABEL 3. Hasil Perhitungan Uji Homogenitas Hasil Belajar Aspek Pengetahuan

\begin{tabular}{lccc}
\hline \multicolumn{1}{c}{ Kelas } & N & Pretest & Varians \\
\multicolumn{1}{c}{ Eksperimen } & 36 & 31,79 & Posttest \\
\hline Kontrol & 36 & 18,23 & 270,37 \\
$\mathrm{~F}_{\text {hitung }}$ & & 1,74 & 327,87 \\
$\mathrm{~F}_{\text {tabel }} \alpha=5 \%$ & 1,76 & 0,82 \\
Syarat & & $\mathrm{F}_{\text {hitung }}<\mathrm{f}_{\text {tabel }}$ & $\mathrm{F}_{\text {hitung }}<\mathrm{f}_{\text {tabel }}$ \\
Status varian & & Homogen & Homogen \\
\hline
\end{tabular}

TABEL 4. Hasil Perhitungan Uji Homogenitas Kemampuan Pemecahan Masalah

\begin{tabular}{lccc}
\hline \multicolumn{1}{c}{ Kelas } & \multicolumn{2}{c}{ Varians } \\
& N & Pretest & Posttest \\
\hline \multicolumn{1}{c}{ Eksperimen } & 36 & 6,30 & 10,52 \\
Kontrol & 36 & 4,91 & 6,30 \\
$\mathrm{~F}_{\text {hitung }}$ & & 0,77 & 1,66 \\
$\mathrm{~F}_{\text {tabel }} \alpha=5 \%$ & 1,76 & 1,76 \\
Syarat & & $\mathrm{F}_{\text {hitung }}<\mathrm{f}_{\text {tabel }}$ & $\mathrm{F}_{\text {hitung }}<\mathrm{f}_{\text {tabel }}$ \\
Status varian & Homogen & Homogen
\end{tabular}

\section{b. Pengujian Hipotesis Hasil Belajar dan Kemampuan Pemecahan Masalah}

Uji hipotesis rata-rata posttest siswa dengan melakukan uji-t dua sampel independen dengan rumus $t$-test separated varian, yaitu jika $t_{\text {hitung }}>t_{\text {tabel }}$ pada taraf signifikan $(\alpha=0,05)$ dan derajat kebebasan $\mathrm{dk}=\mathrm{n} 1+\mathrm{n} 2-2$ jika terdapat perbedaan, maka perlakuan yang diberikan berpengaruh, Ho ditolak dan $\mathrm{H}_{\mathrm{a}}$ diterima dan apabila $\mathrm{t}_{\text {hitung }}<\mathrm{t}_{\text {tabel }}$ maka Ho diterima dan $\mathrm{H}_{\mathrm{a}}$ ditolak. Hasil analisis uji- $\mathrm{t}$ dua sampel independen dapat dilihat pada TABEL 5 dan TABEL 6.

TABEL 5. Hasil Uji-T Hasil Belajar Aspek Pengetahuan

\begin{tabular}{|c|c|c|c|c|c|c|c|}
\hline Hasil & Kelas & $\mathbf{n}$ & $\begin{array}{l}\text { Rata- } \\
\text { rata }\end{array}$ & Varian & $\mathbf{t}_{\text {hitung }}$ & $\begin{array}{c}\mathbf{T}_{\text {tabel }} \\
(\mathbf{d k = 7 0}) \\
\text { taraf } \\
\text { kesalahan } \\
5 \%\end{array}$ & Kesimpulan \\
\hline Posttest & Eksperimen & 36 & $\begin{array}{l}72,82 \\
52,19\end{array}$ & $\begin{array}{l}270,37 \\
32787\end{array}$ & 5,05 & 1,99 & $\begin{array}{c}\text { Terdapat } \\
\text { perbedaan }\end{array}$ \\
\hline
\end{tabular}

TABEL 6. Hasil Uji-T Kemampuan Pemecahan Masalah

\begin{tabular}{|c|c|c|c|c|c|c|c|}
\hline Hasil & Kelas & n & $\begin{array}{c}\text { Rata- } \\
\text { rata }\end{array}$ & Varian & $\mathbf{t}_{\text {hitung }}$ & $\begin{array}{c}\mathbf{T}_{\text {tabel }} \\
(\mathbf{d k}=\mathbf{7 0}) \\
\text { taraf } \\
\text { kesalahan } \\
\mathbf{5 \%}\end{array}$ & Kesimpulan \\
\hline
\end{tabular}




\begin{tabular}{cccccccc}
\hline Posttest & Eksperimen & 36 & 9,13 & 10,52 & 7,55 & 1,99 & $\begin{array}{c}\text { Terdapat } \\
\text { perbedaan }\end{array}$ \\
& Kontrol & 36 & 4,47 & 6,30 & & &
\end{tabular}

\section{Pembahasan}

\section{a. Pengaruh Penggunaan Model Pembelajaran Penemuan Berbantuan Media Animasi Terhadap Hasil Belajar Aspek Pengetahuan}

Hasil penelitian terhadap dua kelas yang dijadikan sebagai sampel penelitian yaitu kelas $\mathrm{X}$ MIPA C sebagai kelas eksperimen dan kelas X MIPA D sebagai kelas kontrol memperlihatkan perbedaan hasil belajar. Perbedaan hasil belajar diperoleh akibat dari adanya perbedaan perlakuan. Pada kelas eksperimen diberikan perlakuan dengan menggunakan model pembelajaran penemuan dengan berbantuan media animasi yang terdiri dari 5 tahapan, yaitu 1) stimulasi atau pemberian rangsangan, 2) identifikasi masalah, 3) pengumpulan data, 4) pengolahan data, 5) pembuktian, dan 6) menarik kesimpulan. Sedangkan pada kelas kontrol tidak diberikan perlakuan sehingga pembelajaran dilaksanakan seperti biasa dengan menggunakan model pembelajaran penemuan. Untuk mengetahui perbedaan hasil belajar kedua kelas maka siswa pada kelas eksperimen dan kelas kontrol diberi soal pretest untuk menguji kemampuan awal siswa sebelum diberi perlakuan serta soal posttest untuk menguji kemampuan akhir siswa setelah diberi perlakuan. Setelah dilakukan pembelajaran dengan menggunakan model pembelajaran penemuan dengan berbantuan media animasi sebagai kelas eksperimen, skor rata-rata posttest yang diperoleh mencapai 72,82. Pada kelas kontrol yang diajarkan dengan menggunakan model pembelajaran penemuan atau tanpa berbantuan media animasi, skor rata-rata posttest hanya mencapai 52,19. Berdasarkan uji perbedaan rata-rata hasil belajar siswa sampel independent menunjukkan bahwa $\mathrm{t}_{\text {hitung }}=5,05>\mathrm{t}_{\text {tabel }}=1,99$ dengan $\mathrm{dk}=70$ pada taraf signifikan 5\% yang berarti terdapat pebedaan hasil belajar aspek pengetahuan yang signifikan antara kelas eksperimen dan kelas kontrol.

Hasil penelitian ini menunjukkan bahwa hasil belajar kelas eksperimen yang diajar dengan menggunakan model pembelajaran penemuan dengan berbantuan media animasi lebih tinggi dibandingkan hasil belajar kelas kontrol yang diajarkan dengan menggunakan model pembelajaran penemuan tanpa berbantuan media animasi. Hasil penelitian ini sesuai dengan hasil penelitian yang telah dilakukan oleh Lestari yang menunjukkan bahwa pada kelas eksperimen yang diajarkan dengan menggunakan model pembelajaran discovery learning terbukti memberikan skor rata-rata hasil belajar kelas eksperimen lebih tinggi dari kelas kontrol, dari hasil penelitiannya didapat $t_{\text {hitung }}>t_{\text {tabel }}$ yaitu $4,569>2,004[6]$.

\section{b. Pengaruh Penggunaan Model Pembelajaran Penemuan Berbantuan Media Animasi Terhadap Kemampuan Pemecahan Masalah}

Kemampuan pemecahan masalah siswa pada kelas eksperimen dan kelas kontrol dapat dilihat dari hasil pretest dan posttest yang telah diberikan pada grafik 2 dan 4. .Aspek penilaian dalam kemampuan pemecahan masalah terdiri dari beberapa tahapan yaitu 1) mengenali masalah, 2) merencanakan strategi, 3) menerapkan strategi dan 4) mengevaluasi solusi. Kemampuan pemecahan masalah diajarkan pada kelas eksperimen maupun kelas kontrol yaitu pada saat mengerjakan soal perhitungan berdasarkan data percobaan praktikum pada lembar kerja siswa. Pada kelas eksperimen melakukan praktikum dengan menggunakan media animasi yaitu media simulasi virtual phet sedangkan pada kelas kontrol menggunakan alat praktikum lab. Setelah dilakukan pembelajaran dengan menggunakan model pembelajaran penemuan dengan berbantuan media animasi sebagai kelas eksperimen, skor rata-rata posttest yang diperoleh mencapai 9,1. Akan tetapi kenaikan skor rata-rata pretest maupun posttest setiap pertemuan tidak stabil. Pada pertemuan ketiga dan keempat hasil skor rata-rata kemampuan pemecahan masalah mengalami penurunan karena adanya beberapa faktor yaitu karena tingkat kesulitan materi yang tinggi pada pertemuan tersebut yang menyebabkan siswa kesulitan dalam mempelajari materi tersebut dibandingkan pada pertemuan pertama dan kedua. 
Lebih lanjut menurut Depkidnas [7] kesulitan belajar dapat disebabkan oleh kelemahan siswa dalam 1) menguasai pengetahuan prasyarat, 2) memahami konsep dari sub konsep materi, 3) mengoperasikan matematika, 4) menerjemahkan soal, dan 5) merencanakan strategi penyelesaian masalah dan menggunakan algoritma untuk menyelesaikan masalah. Hasil penelitian yang dilakukan Muchsin, dkk [8] menyimpulkan bahwa terdapat masalah yang menyebabkan kesulitan belajar siswa karena siswa kesulitan memahami fisika karena materi pelajaran fisika yang padat, mengahapal dan matematis. Pada kelas kontrol yang diajarkan dengan menggunakan model pembelajaran penemuan tanpa berbantuan media animasi, skor rata-rata posttest hanya mencapai 4,4. Berdasarkan uji perbedaan rata-rata kemampuan pemecahan masalah siswa sampel independent menunjukkan bahwa $\mathrm{t}_{\text {hitung }}=7,55>\mathrm{t}_{\text {tabel }}=1,99$ dengan $\mathrm{dk}=70$ pada taraf signifikan $5 \%$ yang berarti terdapat pebedaan kemampuan pemecahan masalah yang signifikan antara kelas eksperimen dan kelas kontrol.

Hasil penelitian ini menunjukkan bahwa kemampuan pemecahan masalah kelas eksperimen yang diajar dengan menggunakan model pembelajaran penemuan dengan berbantuan media animasi lebih tinggi dibandingkan kemampuan pemecahan masalah yang diajarkan dengan menggunakan model pembelajaran penemuan tanpa berbantuan media animasi. Hasil penelitian ini sesuai dengan hasil penelitian yang telah dilakukan oleh Haryanto [9] menunjukkan bahwa media berbantuan komputer dapat meningkatkan kemampuan pemecahan masalah siswa..

\section{KESIMPULAN}

Berdasarkan hasil dan pembahasan maka dapat ditarik kesimpulan bahwa terdapat pengaruh model pembelajaran penemuan terhadap hasil belajar dan kemampuan pemecahan masalah siswa dengan menggunakan media dengan siswa yang dibelajarkan dengan model kooperatif pada taraf signifikan $(\alpha=0,05)$. Dalam pembelajaran dengan menggunakan model pembelajaran penemuan berbantuan media animasi, guru hendaknya dapat meningkatkan kreativitasnya agar siswa dapat melaksanakan pembelajaran dengan baik.

\section{UCAPAN TERIMAKASIH}

Terima kasih saya ucapkan kepada pihak-pihak yang membantu dalam menyusun artikel ini baik secara materi maupun dukungannya. Referensi yang diberikan sangat bermanfaat dan memberikan arahan yang baik bagi saya.

\section{REFERENSI}

[1] Kosasih, Strategi Belajar dan Pembelajaran Implementasi Kurikulum 2013. Bandung: Yrama Widya, 2014.

[2] I Kurniasih and B. Sani, Implementasi Kurikulum 2013 Konsep dan Penerapannya Revisi Kurikulum 2013.: Kata Pena, 2016.

[3] Slameto, Belajar dan Faktor-Faktor yang Mempengaruhinya. Jakarta: PT Rineka Cipta, 2010.

[4] Sugiyono, Metode Penelitian Pendidikan Pendekatan Kuantitatif, Kualitatif, dan R\&D. Bandung: Alfabeta, 2008.

[5] R. B. Syaifulloh and B. Jatmiko, "Penerapan Pembelajaran dengan Model Guided Discovery dengan Lab Virtual Phet untuk Meningkatkan Hasil Belajar Siswa Kelas XI di SMA 1 Tuban pada Pokok Bahasan Teori Kinetik Gas," Jurnal Inovasi Pendidikan, vol. 3, no. 2, pp. 174-179, 2014.

[6] S. Lestari, "Meningkatkan Kemampuan Pemecahan Masalah Fisika Kelas XI IIS 1 SMA Muhammadiyah 2 Yogyakarta Melalui Pembelajaran SEA," Jurnal Ilmiah Guru, vol. 19, no. 2, pp. 66-76, 2015.

[7] A. Rusilowati, "Diagnosis Kesulitan Belajar Fisika Siswa SD, SMP, dan SMA dengan Teknik 
General Diagnostic dan Analytic Diagnostic," in Seminar Nasional MIPA, Yogyakarta, 2007.

[8] Muchsin, "Bahan Ajar Fisika dengan Pendekatan Problem Based Learning," Jurnal Fisika, vol. 4, no. 2, pp. 173-177, 2015.

[9] U. Haryanto, "Peningkatan Kemampuan Memecahkan Masalah Melalui Media Komputer dalam Pembelajaran Matematika pada Siswa SMKN 1 Ngawen," Jurnal Pendidikan Teknologi dan Kejuruan, vol. 22, no. 4, pp. 423-442, 2015.

[10] Kemendikbud, Modul Pelatihan Implementasi Kurikulum 2013 Tahun Ajaran 2014/2015 Mata Pelajaran Fisika SMA. Jakarta: Kementerian Pendidikan Kebudayaan, 2014. 